\title{
Measurements of the vapor pressure of cubic ice and their implications for atmospheric ice clouds
}

\author{
J. E. Shilling, ${ }^{1,2}$ M. A. Tolbert, ${ }^{1}$ O. B. Toon, ${ }^{3}$ E. J. Jensen, ${ }^{4}$ B. J. Murray, ${ }^{5,6}$ \\ and A. K. Bertram ${ }^{5}$ \\ Received 22 April 2006; revised 6 July 2006; accepted 21 July 2006; published 1 September 2006
}

[1] Under conditions commonly found in Earth's atmosphere, water can form two solid phases; hexagonal ice $\left(I_{h}\right)$ and cubic ice $\left(I_{c}\right)$. Recent reports have suggested that $I_{c}$ may form in the atmosphere under a wider range of conditions than previously believed. In light of these reports, the formation of $I_{c}$ has been suggested as one contributing factor for in-situ observations of persistent in-cloud supersaturations in cold cirrus. However, an accurate evaluation of the contribution of $I_{c}$ formation to the observed supersaturations requires knowledge of the saturation vapor pressure of $I_{c}$, which has not been measured. In this manuscript, we report direct measurements of the vapor pressure of $I_{c}$ over the temperature range $180-190 \mathrm{~K}$. Over this temperature range, the vapor pressure of the cubic phase is $10.5 \pm 2.5 \%$ higher than that of the hexagonal phase. Field measurements of in-cloud supersaturations made during CRYSTAL-FACE are also re-analyzed and discussed. Citation: Shilling, J. E., M. A. Tolbert, O. B. Toon, E. J. Jensen, B. J. Murray, and A. K. Bertram (2006), Measurements of the vapor pressure of cubic ice and their implications for atmospheric ice clouds, Geophys. Res. Lett., 33, L17801, doi:10.1029/2006GL026671.

\section{Introduction}

[2] Under ambient atmospheric conditions, two different ice polymorphs can form, hexagonal $\left(\mathrm{I}_{\mathrm{h}}\right)$ and cubic $\left(\mathrm{I}_{\mathrm{c}}\right)$ [Hobbs, 1974]. Although their physical properties are similar, the cubic phase is metastable with respect to the hexagonal phase; therefore, the vapor pressure of $I_{c}$ is necessarily higher than that of $\mathrm{I}_{\mathrm{h}}$ [Eisenberg and Kauzmann, 1969; Hobbs, 1974]. While the vapor pressure of the hexagonal phase is well defined [Marti and Mauersberger, 1993; Murphy and Koop, 2005], there are no quantitative measurements of the vapor pressure of the cubic phase, although one report suggests its vapor pressure is higher than that of $\mathrm{I}_{\mathrm{h}}[$ Kouchi, 1990] and another has analyzed

\footnotetext{
${ }^{1}$ Department of Chemistry and Biochemistry and Cooperative Institute for Research in the Environmental Sciences, University of Colorado, Boulder, Colorado, USA.

${ }^{2}$ Now at Harvard University, Division of Engineering and Applied Sciences, Cambridge, Massachusetts, USA.

${ }^{3}$ Laboratory for Atmospheric and Space Physics, Program in Atmospheric and Oceanic Sciences, University of Colorado, Boulder, Colorado, USA.

${ }^{4}$ NASA Ames Research Center, Moffett Field, California, USA.

${ }^{5}$ Department of Chemistry, University of British Columbia, Vancouver, British Columbia, Canada.

${ }^{6}$ Now at School of Chemistry, University of Leeds, Leeds, UK.
}

Copyright 2006 by the American Geophysical Union. 0094-8276/06/2006GL026671\$05.00 literature calorimetry measurements to bound the $I_{c}$ vapor pressure [Murphy, 2003].

[3] Recent measurements of water vapor in sub-tropical contrail and cirrus clouds have shown persistent ice supersaturations (with respect to $\mathrm{I}_{\mathrm{h}}$ ) of $\mathrm{S}_{\text {ice }}\left(\mathrm{I}_{\mathrm{h}}\right)=1.3$ at temperatures below 202 K [Gao et al., 2004]. Gao et al. [2004] propose that the formation of a new $\mathrm{HNO}_{3}$-containing phase of ice $(\Delta$-ice) is responsible for the supersaturations. The formation of the cubic phase of ice has been proposed to contribute to these measurements [Murphy, 2003; Murray et al., 2005]. While the hexagonal phase of ice has been assumed to predominate under atmospherically relevant conditions, observations of solar halos suggest that $\mathrm{I}_{\mathrm{c}}$ could also exist in the atmosphere [Rikkonen et al., 2000; Whalley, 1981, 1983]. Recently, Murray et al. [2005] demonstrated that several atmospherically relevant solutions freeze to form nearly $100 \% \mathrm{I}_{\mathrm{c}}$ below $\sim 190 \mathrm{~K}$. Above $190 \mathrm{~K}$, the proportions of $I_{c}$ and $I_{h}$ were dependent on the identity of the solution. In light of this study, the cubic form of ice may be more important in the atmosphere than previously believed. Cubic ice might also form in several other venues, including polar stratospheric clouds, noctilucent clouds, as well as clouds on Mars and perhaps Titan.

[4] In this work, we report measurements of the vapor pressure of $I_{c}$ over the temperature range $180-190 \mathrm{~K}$. Our measurements suggest that the formation of $I_{c}$ at cold temperatures, particularly below $195 \mathrm{~K}$, may contribute to the in-cloud supersaturations discussed by Gao et al. [2004].

\section{Experimental}

\subsection{Knudsen Cell Apparatus}

[5] Vapor pressure measurements were conducted in a Knudsen Cell/FTIR-Reflection Absorption Spectroscopy (FTIR-RAS) apparatus [Hudson et al., 2002]. Water partial pressures were measured using an MKS Baratron capacitance manometer $(690 \mathrm{~A})$ with a reported accuracy of $0.08 \%$ of the reading for pressures greater than $1 \times 10^{-6}$ Torr. Temperature was monitored with a T-type thermocouple and controlled by resistively heating against a liquid nitrogen cryostat. The condensed phase was monitored with FTIR spectroscopy. The sensitivity of our FTIR-RAS instrument to changing ice thickness is $\sim 1$ monolayer (ML) under optimum conditions [Zondlo et al., 1997].

\subsection{Ice Film Preparation}

[6] Ice films were prepared by one of two techniques, which dictated the phase formed. Regime 1 ice was deposited at a rate of $1.2 \times 10^{17}$ molecules $/ \mathrm{s}(\sim 30 \mu \mathrm{m} / \mathrm{hr})$ onto the substrate at a temperature of $90 \mathrm{~K}$ to a thickness 


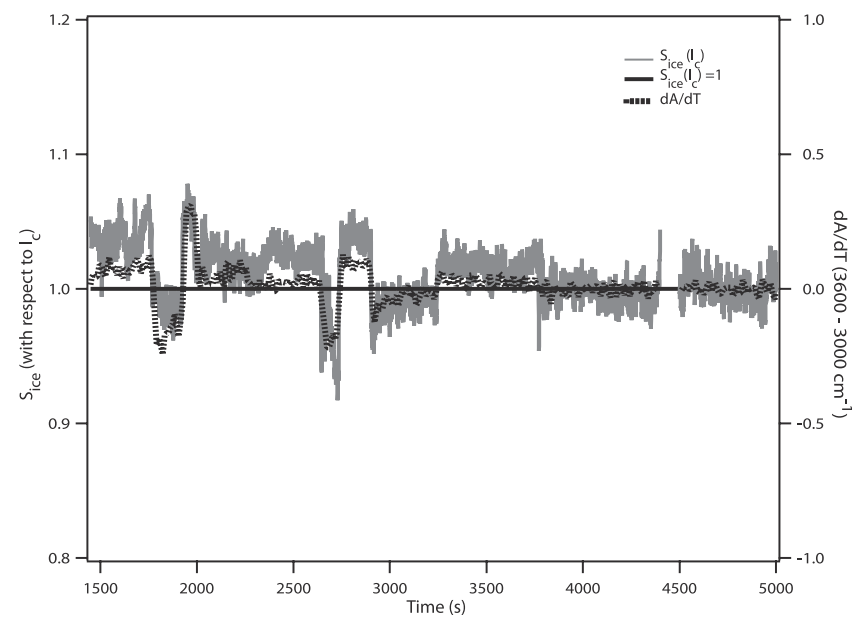

Figure 1. $\mathrm{S}_{\text {ice }}\left(\mathrm{I}_{\mathrm{c}}\right)$ (grey line) and time derivative of the integrated absorbance of the $3600-3000 \mathrm{~cm}^{-1} \mathrm{OH}$ stretching band of ice (dotted line) as a function of time. A horizontal black line has been drawn at $\mathrm{S}_{\text {ice }}\left(\mathrm{I}_{\mathrm{c}}\right)=1$ for clarity. This particular experiment was conducted at $181.2 \mathrm{~K}$ on an $I_{c}$ film. Data taken while the liquid nitrogen cryostat was being filled (4400-4500 s) have been omitted.

of $130-220 \mathrm{~nm}$ (see auxiliary material ${ }^{1}$ ). Under these conditions, vapor deposited water is reported to form the amorphous phase of ice $\left(\mathrm{I}_{\mathrm{a}}\right)$ [Blackman and Lisgarten, 1957; Burton and Oliver, 1936; Hobbs, 1974; Honjo et al., 1956; Shallcross and Carpenter, 1957; Shimaoka, 1960]. After film growth, the substrate was then isolated from the chamber atmosphere and warmed to the measurement temperature at a rate of $\sim 5 \mathrm{~K} / \mathrm{min}$. Amorphous ice is reported to rapidly convert to the cubic phase upon warming [Beaumont et al., 1961; Blackman and Lisgarten, 1957; Burton and Oliver, 1936; Dowell and Rinfret, 1960; Ghormley, 1968; Honjo et al., 1956; Jenniskens and Blake, 1994, 1996; Kohl et al., 2000; Shimaoka, 1960]. To ensure that film thickness has no effect on the measured vapor pressure, thicker ice films (up to $30 \mu \mathrm{m}$ ) were prepared by deposition at this rate and temperature, but for longer timescales. While the method used to form $I_{c}$ in this study differs from the likely formation mechanisms in the atmosphere, the vapor pressure of the resulting $I_{c}$ should depend only on temperature.

[7] Regime 2 ice was deposited at a rate of $2 \times 10^{19}$ molecules/s $(\sim 3000 \mu \mathrm{m} / \mathrm{hr})$ onto the substrate at temperature of $210 \mathrm{~K}$ to a thickness of $13-22 \mu \mathrm{m}$. Under these conditions, vapor deposited water is reported to form the hexagonal phase of ice [Hobbs, 1974; Honjo et al., 1956; Shimaoka, 1960]. The ice was isolated from the chamber atmosphere and cooled to the measurement temperature at a rate of $\sim 1 \mathrm{~K} / \mathrm{min}$. There are no literature reports of polymorphs other than $\mathrm{I}_{\mathrm{h}}$ forming under these conditions.

\subsection{Vapor Pressure Measurements}

[8] The method used for determining the equilibrium vapor pressure of the ice films is illustrated in Figure 1. The grey trace shows the saturation ratio relative to the

\footnotetext{
${ }^{1}$ Auxiliary materials are available in the HTML. doi:10.1029/ 2006 GL026671.
}

equilibrium value of $\mathrm{I}_{\mathrm{c}}$ determined at the end of this experiment at $181.2 \mathrm{~K}$. A solid black line has been drawn at $\mathrm{S}_{\text {ice }}\left(\mathrm{I}_{\mathrm{c}}\right)=1$ for clarity. The dotted line corresponds to the time derivative of the integrated area of the 3600$3000 \mathrm{~cm}^{-1} \mathrm{OH}$ stretching region of ice as measured with reflection absorption infrared spectroscopy. Data taken while the liquid nitrogen cryostat was being filled (4400$4500 \mathrm{~s}$ ) have been omitted. The derivative of the integrated area is used to determine whether the ice film is growing, evaporating, or in equilibrium with the vapor phase. As seen in Figure 1, when the pressure is above the equilibrium pressure, the film grows; when it is decreased below the equilibrium pressure, the film sublimes. The water partial pressure is adjusted until the integrated area is constant $(\mathrm{dA} / \mathrm{dt} \sim 0)$ for a minimum time of 15 minutes in most experiments. The pressure at this point is considered the equilibrium vapor pressure of the ice film.

\subsection{X-Ray Diffraction Measurements}

[9] Because the spectra of $I_{h}$ and $I_{c}$ are identical at mid-IR wavelengths, we are unable to differentiate the two forms based on their spectra [Bertie and Whalley, 1964, 1967; Ockman, 1958]. Therefore, x-ray diffraction studies were conducted in a separate instrument to interrogate the ice phase on an identical substrate and under nearly identical deposition conditions to those used to measure the vapor pressure. The apparatus is similar to the one described by Murray et al. [2005]. The gold substrate was mounted onto a cooling stage inside an evacuated chamber and equipped with Mylar windows for the X-ray measurements. Temperature was monitored with a platinum RTD sensor mounted in the substrate and controlled by resistive heating against a liquid nitrogen reservoir. A gas inlet and leak valve were added to allow controlled amounts of water vapor into the chamber. Water was drawn from a vessel containing $18 \mathrm{M} \Omega$ water that had been degassed. X-ray diffraction patterns presented here were measured with $\mathrm{Cu}-\mathrm{K} \alpha$ radiation. The diffractometer was in the Bragg-Brentano reflection configuration.

[10] Figure 2 shows a series of $x$-ray diffraction patterns obtained during various stages of ice film preparation for one particular ice sample. All traces have been scaled and offset for clarity. Trace A in Figure 2 shows the background diffraction pattern obtained at $90 \mathrm{~K}$ before ice was deposited. The sharp peak at $38.2^{\circ}$ and the weaker one at $44.4^{\circ}$ are caused by the Au substrate. The sharp peaks at $38.5^{\circ}$ and $44.7^{\circ}$ are Bragg diffraction peaks from the Al disk that the Au coating is deposited onto. The weak peak at $40.3^{\circ}$ is from a coating covering the gold substrate. Trace B shows the ice film resulting from the deposition of water vapor at $90 \mathrm{~K}$ and at a rate nearly identical to that used in Regime 1 . As can be seen in this trace, the diffraction pattern is largely featureless, with a broad, relatively weak peak (labeled $\mathrm{I}_{\mathrm{a}}$ ) centered on $24^{\circ}$. Trace $\mathrm{B}$ is in excellent agreement with previously reported diffraction patterns of amorphous ice [Dowell and Rinfret, 1960; Kohl et al., 2000]. After turning off the water vapor flow, this ice sample was then heated to $180 \mathrm{~K}$ at a rate of $5 \mathrm{~K} / \mathrm{min}$.

[11] At a temperature of $154 \pm 5 \mathrm{~K}$, the ice sample was observed to undergo a transition from the amorphous to the cubic phase. Trace $\mathrm{C}$ in Figure 2 shows the diffraction pattern of the resultant ice sample at $180 \mathrm{~K}$. Cubic and 


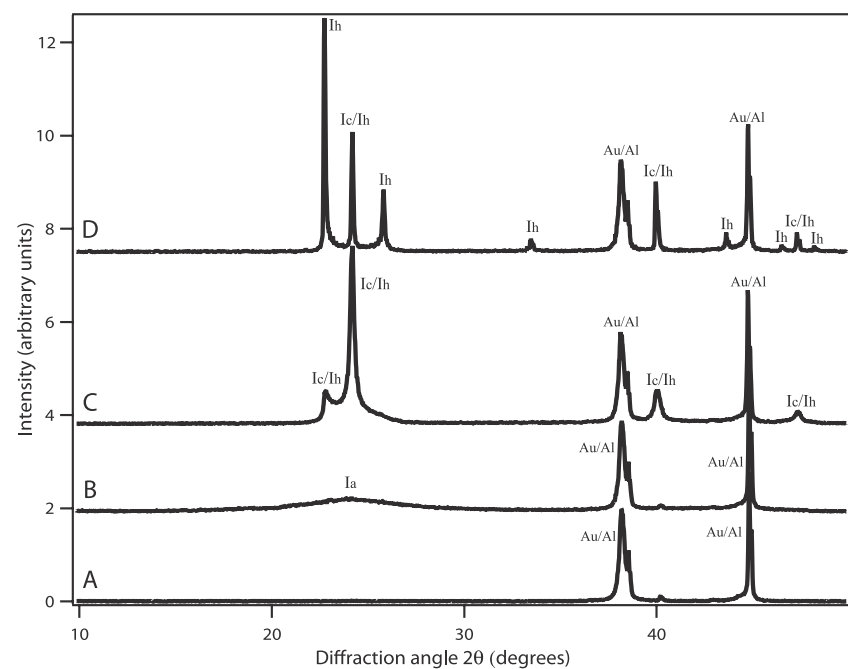

Figure 2. X-ray diffraction patterns of one ice film under a variety of conditions. Patterns have been scaled and offset for clarity. Trace A shows the background diffraction pattern. Trace B shows the ice immediately after deposition under Regime 1 conditions at $90 \mathrm{~K}$. Trace $\mathrm{C}$ shows the diffraction pattern at $180 \mathrm{~K}$ after the film shown in $\mathrm{B}$ has been annealed from $90 \mathrm{~K}$ to $180 \mathrm{~K}$ at a rate of $5 \mathrm{~K} /$ minute. Trace $\mathrm{D}$ shows the ice film after annealing from $180 \mathrm{~K}$ to $210 \mathrm{~K}$ at a rate of $5 \mathrm{~K} /$ minute and cooling back to $180 \mathrm{~K}$. Peaks attributed to the substrate are labeled Au/Al. Peaks attributed to amorphous ice are labeled $\mathrm{I}_{\mathrm{a}}$. Peaks common to $I_{c}$ and $I_{h}$ are labeled $I_{c} / I_{h}$ while peaks unique to $I_{h}$ are labeled $\mathrm{I}_{\mathrm{h}}$. Comparison of $\mathrm{C}$ and $\mathrm{D}$ reveals that $\mathrm{I}_{\mathrm{c}}$ produced by this method is free of $\mathrm{I}_{\mathrm{h}}$ impurities.

hexagonal ice share several peaks, which have been labeled $I_{c} / I_{h}$. There are no strong diffraction peaks unique to $I_{c}$; however, there are several diffraction peaks unique to the hexagonal phase. Therefore, the existence of the cubic phase is indicated by the absence of $\mathrm{I}_{\mathrm{h}}$ features. The diffraction pattern shown in Trace $\mathrm{C}$ is in excellent agreement with previous studies of $\mathrm{I}_{\mathrm{c}}$ [Dowell and Rinfret, 1960; Kohl et al., 2000; Mayer and Hallbrucker, 1987; Murray et $a l ., 2005]$. The feature at $23^{\circ}$ and the distorted nature of the $24^{\circ}$ peak in Trace $\mathrm{C}$ are associated with hexagonal-like stacking faults, which are ubiquitous to $\mathrm{I}_{\mathrm{c}}[K u h s$ et al., 2004; Murray et al., 2005]. The diffraction pattern of the ice film was monitored at $180 \mathrm{~K}$ for approximately 60 minutes without observing the growth of peaks associated with $\mathrm{I}_{\mathrm{h}}$.
This measurement indicates that the lifetime of the cubic phase is greater than 60 minutes at $180 \mathrm{~K}$ and is in agreement with the lifetime determined by Dowell and Rinfret [1960].

[12] After observation at $180 \mathrm{~K}$, the ice film was warmed to $210 \mathrm{~K}$ at a rate of $5 \mathrm{~K} / \mathrm{min}$, held there for approximately one minute, and cooled back to $180 \mathrm{~K}$. Trace D shows the diffraction pattern that resulted from this thermal trajectory. Comparison of Trace D with literature diffraction patterns show excellent agreement with $\mathrm{I}_{\mathrm{h}}$ [Dowell and Rinfret, 1960; Kohl et al., 2000; Mayer and Hallbrucker, 1987; Murray et al., 2005]. The peaks unique to the hexagonal phase have been labeled $I_{h}$ in Figure 2. As can be seen, there are several peaks present in Trace D that are not present in Trace $\mathrm{C}$, verifying the predominance of the hexagonal phase. The $I_{c}$ and $I_{h}$ diffraction patterns exhibit some preferred orientation, which is not unexpected for an ice film grown on a substrate [Dowell and Rinfret, 1960].

[13] Additional experiments in the x-ray diffraction instrument were conducted using varying deposition rates and times at $90 \mathrm{~K}$. Deposition always produced amorphous ice, which always converted rapidly to $I_{c}$ near $154 \mathrm{~K}$, regardless of film thickness or deposition rate. Ice deposited under Regime 2 conditions always resulted in the formation of the hexagonal phase of ice.

\section{Results and Discussion}

\subsection{Vapor Pressure of $I_{c}$}

[14] The data obtained for the vapor pressure of ice films as a function of growth regime are show in Table 1 for the temperature range 180-190 K. Temperatures shown in Table 1 are determined by referencing the vapor pressure of $\mathrm{I}_{\mathrm{h}}$ films to the literature data [Murphy and Koop, 2005]. These calibrated temperatures are identical, within error, to those read from a thermocouple attached to the back of the substrate on which the ice films are grown. The reported pressures are the averages of at least six separate experiments performed at each temperature with the indicated standard deviation. As seen in Table 1, the equilibrium vapor pressures of $I_{c}$ films are higher than those of $I_{h}$. While the difference is small, it is statistically significant. Over the temperature range studied, the $\mathrm{I}_{\mathrm{c}}$ films have an average vapor pressure that is $10.5 \pm 2.5 \%$ higher than the $\mathrm{I}_{\mathrm{h}}$ films. This vapor pressure difference agrees well with that predicted by Murphy [2003] from the available thermodynamic phase change data. The vapor pressure of the ice film was also independent of its thickness for a given set of deposition conditions.

Table 1. Measured Vapor Pressure of $I_{c}$ and $I_{h}$ Films

\begin{tabular}{|c|c|c|c|c|c|c|}
\hline $\mathrm{T}^{\mathrm{a}}{ }^{\mathrm{K}}$ & $\begin{array}{c}\text { Deposition } \\
\text { Regime }\end{array}$ & $\begin{array}{c}\text { Ice } \\
\text { Phase }\end{array}$ & $\mathrm{P},{ }^{\mathrm{b}}$ Torr & $1 \sigma$ & $\begin{array}{c}\text { Difference, } \\
\% \text { of } \mathrm{I}_{\mathrm{h}}\end{array}$ & $\begin{array}{c}\Delta \Delta \mathrm{H}_{\text {sub }}, \\
\mathrm{J} / \mathrm{mole}\end{array}$ \\
\hline 181.3 & $\begin{array}{l}1 \\
2\end{array}$ & $\begin{array}{l}\mathrm{I}_{\mathrm{c}} \\
\mathrm{I}_{\mathrm{b}}\end{array}$ & $\begin{array}{l}5.70 \times 10^{-5} \\
5.16 \times 10^{-5}\end{array}$ & $\begin{array}{l}7.8 \times 10^{-7} \\
1.0 \times 10^{-6}\end{array}$ & 10.5 & 150 \\
\hline 186.4 & $\begin{array}{l}1 \\
2\end{array}$ & $\begin{array}{l}I_{c} \\
I_{h}\end{array}$ & $\begin{array}{l}1.44 \times 10^{-4} \\
1.30 \times 10^{-4}\end{array}$ & $\begin{array}{l}1.6 \times 10^{-6} \\
6.3 \times 10^{-7}\end{array}$ & 10.8 & 159 \\
\hline 191.2 & $\begin{array}{l}1 \\
2 \\
\end{array}$ & $\begin{array}{l}I_{c} \\
I_{h}\end{array}$ & $\begin{array}{l}3.31 \times 10^{-4} \\
3.00 \times 10^{-4}\end{array}$ & $\begin{array}{l}3.1 \times 10^{-6} \\
1.5 \times 10^{-6} \\
\end{array}$ & 10.3 & 156 \\
\hline
\end{tabular}

${ }^{\mathrm{a}}$ Temperature was calibrated by referencing the $\mathrm{I}_{\mathrm{h}}$ vapor pressure to literature data [Murphy and Koop, 2005].

${ }^{b}$ Reported vapor pressure measurements represent the average of at least six separate experiments. 


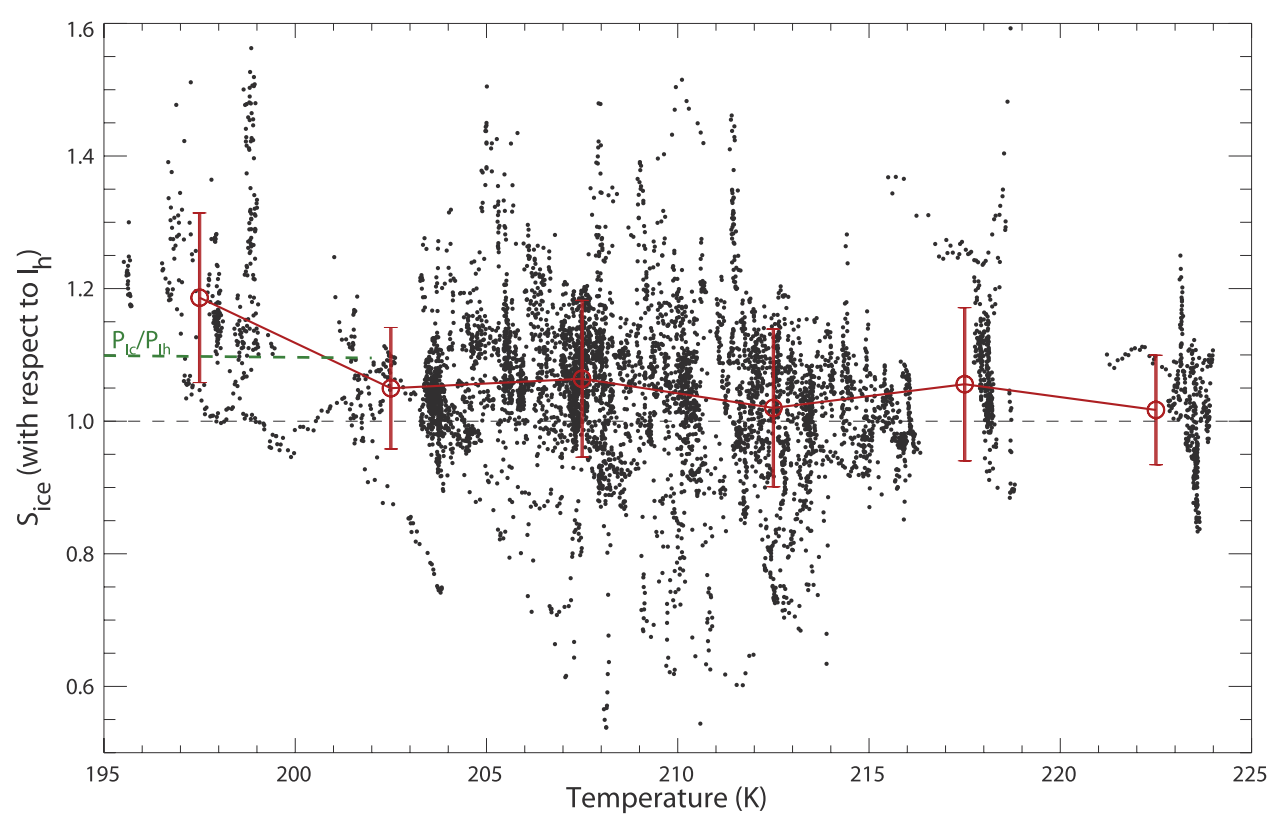

Figure 3. Cirrus in-cloud supersaturations (with respect to $\mathrm{I}_{h}$ ) observed during the NASA CRYSTAL-FACE mission. Data have been re-analyzed according to the procedure outlined in the text. Error bars are 1 standard deviation from the mean. The grey dashed line is saturation relative to hexagonal ice. The green dashed line illustrates the saturation relative to cubic ice.

[15] The relative vapor pressures of $I_{c}$ and $I_{h}$ can be used to determine the difference in their thermodynamic stability. The difference in the latent heat of sublimation $\left(\Delta \Delta \mathrm{H}_{\text {sub }}\right)$ for $I_{h}$ and $I_{c}$ is given by equation (1), where $P_{I c}$ is the vapor pressure of $I_{c}$

$$
\ln \left(\frac{P_{I c}}{P_{I h}}\right)=\frac{\Delta \Delta H_{s u b}}{R T}
$$

at the measurement temperature, $\mathrm{P}_{\mathrm{Ih}}$ is the vapor pressure of hexagonal ice at the same temperature, $\mathrm{R}$ is the gas constant, and $\mathrm{T}$ is the temperature. In this calculation, it is assumed that the pre-exponential for the vapor pressure of both ice phases is equal. The values of $\Delta \Delta \mathrm{H}_{\text {sub }}$ for each measurement temperature are listed in Table 1 . As can be seen in Table 1, the $\Delta \Delta \mathrm{H}_{\text {sub }}$ values are independent of temperature and average $155 \pm 30 \mathrm{~J} /$ mole over our temperature range. This difference in sublimation enthalpies is equal to the latent heat for the transition from $I_{c}$ to $I_{h}$ that has been determined in literature calorimetry studies. Calorimetric measurement of the latent heat of transformation exhibit a great deal of scatter [Ghormley, 1968; Handa et al., 1986; Johari, 1998; Kohl et al., 2000; Mayer and Hallbrucker, 1987]. However, our measured value of $\Delta \Delta \mathrm{H}_{\text {sub }}=155 \pm$ $30 \mathrm{~J} / \mathrm{mole}$ falls in the range of reported latent heats of transformation, which range from $<22.6 \mathrm{~J} /$ mole [Ghormley, 1968 ] to $160 \mathrm{~J} / \mathrm{mole}$ [Sugisaki et al., 1968].

\subsection{Re-Analysis of Field Measurements}

[16] Our measured vapor pressure of $I_{c}$ can be used to constrain the contribution of $I_{c}$ formation to the observations of persistent in-cloud supersaturations (with respect to $\mathrm{I}_{\mathrm{h}}$ ) at temperatures below $202 \mathrm{~K}$ discussed by Gao et al. [2004]. We have re-analyzed the water vapor measurements presented by Gao et al. [2004] as follows. Two instruments were used to measure water vapor on the NASA WB-57 aircraft during CRYSTAL-FACE: the Harvard water vapor instrument (HWV) and the JPL tunable diode laser hy- grometer (JLH). Gao et al. [2004] used HWV to calculate ice saturation ratios within cirrus [Gao et al., 2004]. However, when the cloud ice water content is high, sublimation of crystals in the inlet of the HWV can result in anomalously high water vapor measurements [Jensen et al., 2005]. JLH is not as accurately calibrated as HWV, but the JLH measurements have higher precision and are unaffected by clouds. Here, we have used JLH measurements within cirrus normalized to HWV measurements in clear-sky regions on either side of each cloud pass. Further, we have only included measurements when the cloud surface area density was large enough such that the time scale for quenching of supersaturation was less than 3 minutes, and we have excluded times when the vertical wind speed was greater than $0.5 \mathrm{~m} / \mathrm{s}$. This restriction should ensure that we are only including time periods when the water vapor was approximately in thermodynamic equilibrium with the ice crystals present. The primary difference between our analysis and the Gao et al. [2004] analysis is the use of JLH data to avoid the inlet sublimation effect.

[17] The $S_{\text {ice }}$ values (relative to $I_{h}$ ) determined using this procedure are shown in Figure 3. At temperatures greater than about $202 \mathrm{~K}$ the clouds are, on average, within 5-10\% of saturation, with error bars overlapping the $I_{h}$ vapor pressure. The in-cloud supersaturations at colder temperatures are still apparent, but the supersaturations (about 20\%) are less than that reported by Gao et al. [2004] (30\%). Below $202 \mathrm{~K}$, the in-cloud relative humidities are, on average, about $120 \%$, with error bars overlapping the $\mathrm{I}_{\mathrm{c}}$ vapor pressure. Therefore, the formation of cubic ice at $\mathrm{T}<202 \mathrm{~K}$ may significantly contribute to the persistent in-cloud water supersaturations discussed by Gao et al. [2004], assuming that the cloud age at the time of the measurements is small compared to the $I_{c}$ to $I_{h}$ conversion time. We note that incloud excursions of $\mathrm{RH}_{\mathrm{i}}$ significantly above (e.g., $\mathrm{RH}_{\mathrm{i}}=$ $150 \%$ ) and below (e.g., $\mathrm{RH}_{\mathrm{i}}=70 \%$ ) $\mathrm{I}_{\mathrm{h}}$ saturation remain unexplained. One possible cause of these excursions is cloud 
inhomogeneity. The $1 \mathrm{~Hz}$ temperature and water vapor measurements result in an averaging over $200 \mathrm{~m}$ along the flight path, which may include highly saturated or subsaturated clear air.

\section{Atmospheric Implications}

[18] These measurements of the vapor pressure of $I_{c}$ should help to reduce the uncertainty associated with modeling cirrus cloud properties at temperatures below $200 \mathrm{~K}$ where $\mathrm{I}_{\mathrm{c}}$ is expected to form. Murphy [2003] demonstrated that inclusion of $\mathrm{I}_{\mathrm{c}}$ into a cloud model lead to the formation of larger ice crystals and enhanced dehydration of air parcels below $200 \mathrm{~K}$. Furthermore, Jensen and Pfister [2005] found that in-cloud supersaturations lead to a $0.5-1$ ppmv increase in stratospheric water vapor content. Redistribution of water vapor in the upper troposphere and lower stratosphere is reported to affect polar stratospheric cloud formation and ozone destruction [Solomon et al., 1986; Toon et al., 1989] and the Earth's radiation budget [Comstock et al., 2002; Forster and Shine, 2002]. Because cirrus and sub-visible cirrus typically form at low temperatures $(<190 \mathrm{~K})$ in the tropics, $\mathrm{I}_{\mathrm{c}}$ particles may be more prevalent in this region than previously assumed.

[19] Acknowledgments. The authors thank D. Murphy for comments on the manuscript and the Harvard water vapor measurement team and B. Herman for use of and discussions concerning the HWV and JLH data, respectively. Partial support for this work was provided by the National Science Foundation. J. E. S acknowledges support from a NASA ESS fellowship. A. K. B. and B. J. M. acknowledge funding from The Canadian Foundation for Climate and Atmospheric Sciences, the Natural Science and Engineering Research Council of Canada, and the Canada Foundation for Innovation.

\section{References}

Beaumont, R. H., H. Chihara, and J. A. Morrison (1961), Transitions between different forms of ice, J. Chem. Phys., 34, 1456-1457.

Bertie, J. E., and E. Whalley (1964), Infrared spectra of ices Ih and Ic in the range 4000-350 $\mathrm{cm}^{-1}$, J. Chem. Phys., 40, 1637-1645.

Bertie, J. E., and E. Whalley (1967), Optical spectra of disordered crystals: II. Infrared spectrum of ice Ih and Ice Ic from $360-50 \mathrm{~cm}^{-1}, J$. Chem. Phys., 46, $1271-1284$.

Blackman, M., and N. D. Lisgarten (1957), The cubic and other structural forms of ice at low temperature and pressure, Proc. R. Soc. London, Ser. A, 239, 93-107.

Burton, E. F., and W. F. Oliver (1936), The crystal structure of ice at low temperatures, Proc. R. Soc. London, Ser. A, 153, 166-172.

Comstock, J. M., T. P. Ackerman, and G. G. Mace (2002), Ground-based remote sensing of tropical cirrus clouds at Nauru Island: Cloud statistics and radiative impacts, J. Geophys. Res., 107(D23), 4714, doi:10.1029/ 2002JD002203.

Dowell, L. G., and A. P. Rinfret (1960), Low-temperature forms of ice as studied by x-ray diffraction, Nature, 188, 1144-1148.

Eisenberg, D., and W. Kauzmann (1969), Ice, in The Structure and Properties of Water, pp. 71-147, Oxford Univ. Press, New York.

Forster, P. M. F., and K. P. Shine (2002), Assessing the climate impact of trends in stratospheric water vapor, Geophys. Res. Lett., 29(6), 1086, doi:10.1029/2001GL013909.

Gao, R. S., et al. (2004), Evidence that nitric acid increases relative humidity in low-temperature cirrus clouds, Science, 303, 516-520.

Ghormley, J. A. (1968), Enthalpy changes and heat-capacity changes in the transformations from high-surface-area amorphous ice to stable hexagonal ice, J. Chem. Phys., 48, 503-508.

Handa, Y. P., D. D. Klug, and W. Whalley (1986), Difference in energy between cubic and hexagonal ice, J. Chem. Phys., 84, 7009-7010.

Hobbs, P. V. (1974), Ice Physics, Oxford Univ. Press, New York.

Honjo, G., N. Kitamura, K. Shimaoka, and K. Mihama (1956), Low temperature specimen method for electron diffraction and electron microscopy, J. Phys. Soc. Jpn., 11(5), 527-536.

Hudson, P. K., M. A. Zondlo, and M. A. Tolbert (2002), The interaction of methanol, acetone, and acetaldehyde with ice and nitric acid-doped ice: Implications for cirrus clouds, J. Phys. Chem., 106, 2882-2888.
Jenniskens, P., and D. F. Blake (1994), Structural transitions in amorphous water ice and astrophysical implications, Science, 265, 753-756.

Jenniskens, P., and D. F. Blake (1996), Crystallization of amorphous water ice in the solar system, Astrophys. J., 473, 1104-1113.

Jensen, E., and L. Pfister (2005), Implications of persistent ice supersaturation in cold cirrus for stratospheric water vapor, Geophys. Res. Lett., 32 , L01808, doi:10.1029/2004GL021125.

Jensen, E., L. Pfister, T. Bui, A. Weinheimer, E. Weinstock, J. Smith, J. Pittman, D. Baumbarder, P. Lawson, and M. J. McGill (2005), Formation of a tropopause cirrus layer observed over Florida during CRYSTAL-FACE, J. Geophys. Res., 110, D03208, doi:10.1029/ 2004JD004671.

Johari, G. P. (1998), On the coexistence of cubic and hexagonal ice between 160 and 240 K, Philos. Mag. B, 78(4), 375-383.

Kohl, I., E. Mayer, and A. Hallbrucker (2000), The glassy water-cubic ice system: A comparative study by X-ray diffraction and differential scanning calorimetry, Phys. Chem. Chem. Phys., 2, 1579-1586.

Kouchi, A. (1990), Evaporation of $\mathrm{H}_{2} \mathrm{O}-\mathrm{CO}$ ice and its astrophysical implications, J. Cryst. Growth, 99, 1220-1226.

Kuhs, W. F., G. Genova, D. K. Staykova, and T. Hansen (2004), Ice perfection and onset of anomalous preservation of gas hydrates, Phys. Chem Chem. Phys., 6, 4917-4920.

Marti, J., and K. Mauersberger (1993), A survey and new measurements of ice vapor pressure at temperatures between 170 and $250 \mathrm{~K}$, Geophys. Res. Lett., 20(5), 363-366.

Mayer, E., and A. Hallbrucker (1987), Cubic ice from liquid water, Nature, $325,601-602$.

Murphy, D. M. (2003), Dehydration in cold clouds is enhanced by a transition from cubic to hexagonal ice, Geophys. Res. Lett., 30(23), 2230, doi:10.1029/2003GL018566.

Murphy, D. M., and T. Koop (2005), Review of the vapour pressures of ice and supercooled water for atmospheric applications, Q. J. R. Meteorol. Soc., 131, 1539-1565.

Murray, B. J., D. A. Knopf, and A. K. Bertram (2005), The formation of cubic ice under conditions relevant to Earth's atmosphere, Nature, 434, 202-205.

Ockman, N. (1958), The infra-red and Raman spectra of ice, Adv. Phys., 7, $199-220$

Rikkonen, M., M. Sillanpaa, L. Virta, D. Sullivan, J. Moilanen, and I. Luukkonen (2000), Halo observations provide evidence of airborne cubic ice in the Earth's atmosphere, Appl. Opt., 39(33), 6080-6085.

Shallcross, F. V., and G. B. Carpenter (1957), X-ray diffraction study of the cubic phase of ice, J. Chem. Phys., 26, 782-784.

Shimaoka, K. (1960), Electron diffraction study of ice, J. Phys. Soc. Jpn., 15(1), 106-119.

Solomon, S., R. R. Garcia, R. S. Rowland, and D. J. Wuebbles (1986), On the depletion of Antarctic ozone, Nature, 321, 755-758.

Sugisaki, M., H. Suga, and S. Seki (1968), Calorimetric study of the glassy state: IV. Heat capacities of glassy water and cubic ice, Bull. Chem. Soc. Jpn., 41, 2591-2599.

Toon, O. B., R. P. Turco, J. Jordan, J. Goodman, and G. Ferry (1989), Physical processes in polar stratospheric ice clouds, J. Geophys. Res., 94(D9), 11,359-11,380.

Whalley, E. (1981), Scheiner's halo: Evidence for ice Ic in the atmosphere, Science, 211, 389-390.

Whalley, E. (1983), Cubic ice in nature, J. Phys. Chem., 87, 4174-4179.

Zondlo, M. A., T. B. Onasch, M. S. Warshawsky, M. A. Tolbert, G. Mallick, P. Arentz, and M. S. Robinson (1997), Experimental studies of vapor-deposited water-ice films using grazing-angle FTIRreflection absorption spectroscopy, J. Phys. Chem. B, 101(50), $10,887-10,895$.

A. K. Bertram, Department of Chemistry, University of British Columbia, 2036 Main Mall, Vancouver, BC, Canada V6T 1 Z1. (bertram@chem.ubc.ca)

E. J. Jensen, NASA Ames Research Center, Mail Stop 2454, Moffett Field, CA 94035, USA. (ejensen@cirrus.arc.nasa.gov)

B. J. Murray, School of Chemistry, University of Leeds, Woodhouse Lane, Leeds, LS2 9TJ, UK. (bmurray@chem.ubc.ca)

J. E. Shilling, Harvard University, Division of Engineering and Applied Sciences, 40 Oxford Street, Cambridge, MA 02138, USA. (shilling@deas. harvard.edu)

M. A. Tolbert, Department of Chemistry and Biochemistry and Cooperative Institute for Research in the Environmental Sciences, University of Colorado, Campus Box 216, Room 318, Boulder, CO 80309-0216, USA. (tolbert@colorado.edu)

O. B. Toon, Laboratory for Atmospheric and Space Physics, Program in Atmospheric and Oceanic Sciences, University of Colorado, Campus Box 392, Boulder, CO 80309-0392, USA. (toon@lasp.colorado.edu) 